\section{Equidade, justiça e a judicialização da saúde}

Gualberto, João Marcos Souza

Mestrando - Programa de Pós-graduação em Bioética UnB.E-mail: gualberto781@gmail.com.

\section{Holanda, Marianna}

Docente - Programa de Pós-graduação em Bioética - UnB

PALAVRAS CHAVE: Equidade; Justiça; Judicialização; NAT-JUS; Saúde

INTRODUÇÃO: A judicialização da saúde é um fenômeno referente às demandas judiciais que visam ao acesso dos requerentes a serviços e materiais da saúde (cirurgias, medicamentos e leitos de UTIs), de modo que após a apreciação pelo judiciário, é possível que se obrigue o Poder Executivo a garantir aquilo que foi demandado pelo cidadão. Desta forma, tais processos judiciais ao mesmo tempo que protegem o cidadão da omissão do Estado no fornecimento dos serviços de saúde, podem ocasionar desequilíbrios nas contas públicas tendo afronta à equidade na distribuição dos escassos recursos públicos, visto que há também uma desigualdade no acesso à justiça entre os grupos sociais. Diante de tais dilemas, faz necessário discutir os aspectos positivos e negativos da judicialização da saúde e seus impactos na organização orçamentária e financeira dos recursos a serem investidos neste setor, além de propor soluções para se evitar iniquidades e injustiças na distribuições dos recursos públicos em saúde, através das discussões bioéticas sobre os impactos na gestão desses recursos com reflexos nas populações vulneráveis. METODOLOGIA: Estudo qualitativo através da análise dos dados encontrados na literatura sobre a judicialização da saúde. RESULTADOS E DISCUSSÕES: a Constituição Federal ${ }^{1}$ de 1988 reconhece no seu art. 196 que "Saúde é um direito de todos e um dever do Estado", assim, cabe ao poder público garantir o acesso do cidadão aos serviços de saúde, e, quando este é omisso em suas obrigações, cabe ao Poder Judiciário ser $\mathrm{o}$ instrumento de defesa dos direitos constitucionais $^{2}$. Porém, é fundamental refletir que quando há estas demandas judiciais, objetiva-se o atendimento às individualidades, as quais muitas vezes são pautadas em interesses econômicos das indústrias farmacêuticas ${ }^{3}$ e servem a uma parcela elitista da população, demonstrando a habitualidade do fato dos demandantes serem provenientes em sua maioria (alguns trabalhos apontam para 63\%) de bairros ricos e dotados de elevadas escolaridades, o que de fato, impactua na equidade quanto à distribuição dos recursos públicos para atender às populações mais vulneráveis, o que permite reletir sobre seus obstáculos no acesso ao judiciário ${ }^{4}$. CONCLUSÕES: A judicialização da saúde é um instrumento importante para as garantias dos direitos fundamentais quando o Poder Executivo é omisso nas demandas das políticas em saúde, no entanto, é necessário que se tenha apoio técnico-científico para auxiliar os magistrados nas decisões quanto às demandas em saúde (sobretudo procedimentos médicos e medicações de alto custo), de modo que haja embasamento previsto na literatura científica multidisciplinar, afim de que se possa decidir em função da real efetividade dos tratamentos propostos. Daí a importância do NAT-JUS (Núcleo de Assistência Técnica ao Judiciário), o qual ao se avaliar as demandas tecnicamente, permite-se que haja decisões fundamentadas e previne-se as consequentes iniquidades e injustiças nas distribuições dos escassos recursos públicos em saúde.

AGRADECIMENTOS. Ao Tribunal de Justiça do Distrito Federal e Territórios e Programa de Mestrado em Bioética da Cátedra UNESCO da UnB.

\section{REFERÊNCIAS}

[1] Brasil, Constituição da República Federativa do Brasil. Presidência da República (1988) - Casa Civil. Disponível no site: http://www.planalto.gov.br.

[2] S.R. RODRIGUES, Judicialização: possível caminho à efetivação do direito à saúde no Brasil. Revista Jurídica da Escola Superior do Ministério Público de São Paulo, P 6872., (2012); Disponível em: <http://www.esmp.sp.gov.br>.

[3] S. HULL; D. A. KEEN, Phys. Rev. B 59, 750 (1999).F. Vieira and P. Zucchi, Distorções causadas pelas ações judiciais à política de medicamentos no Brasil. Rev. Saúde Pública. P 41, 214-222 (2007).

[4] G.S. NUNES, P.B. ALLEN, J.L. MARTINS, Phys. Rev. B 57, 5098 (1998). A. Chieffi and R. Barata, Judicialização da política de assistência farmacêutica e equidade. Rev. Saúde Pública. P 25, 1839-1849 (2009). 